\title{
Study of the effectiveness of training Malian social and health agents in female genital cutting issues and in educating their clients
}

\author{
Nafissatou J. Diop \\ Population Council \\ Fatoumata Traore \\ Habibatou Diallo \\ Ousmane Traore \\ Aissa Haidara Toure
}

See next page for additional authors

Follow this and additional works at: https://knowledgecommons.popcouncil.org/departments_sbsr-rh

Part of the Community-Based Research Commons, Gender and Sexuality Commons, International Public Health Commons, Obstetrics and Gynecology Commons, Public Health Education and Promotion Commons, and the Women's Health Commons

How does access to this work benefit you? Let us know!

\section{Recommended Citation}

Diop, Nafissatou J., Fatoumata Traore, Habibatou Diallo, Ousmane Traore, Aissa Haidara Toure, Youssouf Diallo, Madina Sangare, Fatoumata Tandia Keita, and Attaher Toure. 2007. "Study of the effectiveness of training Malian social and health agents in female genital cutting issues and in educating their clients," Final report. Bamako: Division of Family and Community Health, Population Council, Association for the Support and Development of Population Activities, Republic of Mali. 


\section{Authors}

Nafissatou J. Diop, Fatoumata Traore, Habibatou Diallo, Ousmane Traore, Aissa Haidara Toure, Youssouf Diallo, Madina Sangare, Fatoumata Tandia, and Keita Attaher Toure 


\title{
STUDY OF THE EFFECTIVENESS OF TRAINING MALIAN SOCIAL AND HEALTH AGENTS IN FEMALE GENITAL CUTTING ISSUES AND IN EDUCATING THEIR CLIENTS
}

Division of Family and Community Health

Madina Sangaré

Fatoumata Tandia

Keita Attaher Touré

Population Council

Operations Research and Technical Assistance in Africa

Nafissatou J Diop

Association for the Support and Development of Population Activities

\author{
Fatoumata Traoré \\ Habibatou Diallo \\ Ousmane Traoré \\ Aissa Haidara Touré \\ Youssouf Diallo \\ Republic of Mali \\ One Faith, One People, One Purpose
}


PERSONS WHO CONTRIBUTED TO THE IMPLEMENTATION OF THIS PROJECT

Association for the Support and Development of Population Activities

Troare Fatoumata Toure

Dr. Traore Ousmane

Dr. Sylla Habibatou Diallo

Dr. Diallo Youssouf

Dr. Toure Aissa Haidara

Population Council

Dr. Nafissatou J. Diop

Division of Family And Community Health

Dr. Sangare Madina

Dr. Tandia F.D. Keita

Dr. Toure Attaher

Regional Direction from Bamako Public Health

Mme Dembele Kadia Ndiaye

Dr. Traore Fatoumata Traore

Regional Direction from Segou Public Health

Mme Diakite Djénéba Coulibaly

Dr. Magassa Nama 


\section{CONTENTS}

List of tables and graphs

Acknowledgements

Executive Summary

I. Introduction
A. Context
B. Justification of this study
C. Institutional framework

II. Objectives and Hypotheses
A. Objectives
B. Hypotheses

III. Methodology
A. Research process
B. Activities
C. Sampling and development of data collection tools
D. Data collection
E. Data treatment and analysis
F. Limits of this study

IV. Dissemination and Use of Results

V. Presentation of Main Results and Recommendations
A. Presentation of sampling
B. FGC profile in Mali

1. Prevalence rates of different FGC types

2. FGC-related health complications

3. Complications reported by clients who were interviewed

4. General conclusions and recommendations regarding FGC cases 
C. Health service providers

1. FGC knowledge among health service providers

2. Health service providers' experience with FGC complications

3. Providers' attitudes toward FGC

4. Medicalization of FGC

5. Conclusions and recommendations regarding health care providers

D. Impact of the interventions

1. Implication of health care personnel in the anti-FGC campaign

2. IEC activities conducted in health service facilities

3. Impact of the interventions on clients

4. Conclusions and recommendations concerning IEC activities in health facilities

VI. Overall Conclusions and Recommendations

Bibliography 


\section{LIST OF TABLES AND GRAPHS}

\section{TABLES}

Table 1: Social/health services facilities of this study according to location

Table 2: Health facilities in control and test sites

\section{GRAPHS}

Graph 1: Ethnic distribution of clients observed

Graph 2: Distribution of circumcised clients by FGC type

Graph 3: Distribution of clients observed by FGC type and ethnicity

Graph 4: Complications at delivery according to FGC status

Graph 5: Knowledge of FGC complications among providers in test sites

Graph 6: Immediate and delayed FGC-related consequences encountered by providers

Graph 7: Providers' opinions on whether uncircumcised girls have loose morals

Graph 8: Providers who think FGC does not pose a health risk if performed in a hygienic environment

Graph 9: Medicalization of FGC in Mali

Graph 10: Providers' view of their active role in anti-FGC activities

Graph 11: IEC materials in social/health service facilities of test and control sites

Graph 12: FGC counseling given during client visits in test and control sites

Graph 13: Clients' opinions regarding FGC as a safe practice if performed in a medical context 


\section{ACKNOWLEDGEMENTS}

This study was made possible thanks to the active participation of the Ministère de la Santé, des Personnes Agées et de la Solidaritie (MSPAS) and the Association de Soutien au Développement des activités de Population (ASDAP) in Mali and to the Operations Research/Technical Assistance Project (OR/TA II) in Africa run by the Population Council and to the financial support of USAID.

I take this opportunity to express my sincere gratitude to the Direction Nationale de la Santé Publique, Division Santé Familiale et Communautaire (national office of public health, family and community health division), Directions Régionales de la Santé Publique (regional offices of public health) in Bamako and Segou, and all of the health facilities which served as research sites in this pilot study for their wholehearted collaboration and the commitment of their personnel to this study.

I wish to congratulate the team at ASDAP and all the consultants who contributed to this project. My special thanks go to our collaborators at the Population Council in Dakar, Bamako, Nairobi, and New York for their technical assistance and capacity building in operations research methods. I also wish to thank Mme. Assitan Diallo who initiated this project.

I would like to use this opportunity to express my appreciation to USAID for their commitment to our efforts to improve the quality of health care services and of the population's well-being in Mali.

At this time, I would also like to express my wish that the results of this study might contribute to eradicating female genital mutilation.

Mme. TROARE Fatoumata TOURE

President of ASDAP 


\section{EXECUTIVE SUMMARY}

This study was conducted by the Association de Soutien au Développement des Activités de Population (ASDAP) and the Division de la Santé Familiale et Communautaire (DSFC) of the Ministry of Health in Bamako and Segou regions. The Population Council's Africa Operations Research/Technical Assistance II project provided technical assistance throughout the project.

Introduction: Activities aimed at reducing the practice of Female Genital Cutting (FGC) in Mali have mostly been geared towards raising awareness among population subgroups: women, opinion leaders, etc. In particular, efforts to convert traditional circumcisers into agents for behavior change and encouraging them to change their occupation to other income-generating activities have been tried by many NGOs in Mali. After two decades of campaigning against FGC in Mali, it is time to recognize that the results are not satisfactory when compared to the levels of human and financial investment.

One of the approaches recommended by the World Health Organization (WHO) is to use health personnel in reducing the practice. In addition, WHO has made clear statements against the medicalization of all types of FGC in any health facility, whether in hospitals, clinics, or other health centers.

The following characterizes the situation in Mali:

- Increasingly, FGC is performed by health personnel and at medical centers at the request of parents who hope to prevent risks of accidents or future health problems;

- The daughters of health professionals are exposed to the same risk of being cut as all other Malian girls;

- The health problems related to FGC and the required care and treatment for women and girls who suffer from subsequent complications, are not covered in the training curriculum of social / health workers.

The study objectives were to:

- Increase the knowledge and improve attitudes of clinical personnel on health complications of FGC.

- Reduce the proportion of clinical personnel who are willing to circumcise girls based on requests from the parents.

- Increase the proportion of clients coming to health facilities who receive messages against FGC and who know the associated problems.

- Improve the skills of health personnel in identifying and treating medical complications related to FGC.

- Describe the prevalence of different types of FGC and associated health complications in women who visit health facilities.

Description of the interventions: The interventions consisted of three main activities. 1) the training of clinical staff in FGC, its health-related complications and in IEC activities; 2) the introduction of FGC-related IEC activities within health talks at the clinics and during 
individual consultations with clients whenever feasible; 3) the supervision of trained health staff.

Research methodology: Four hypotheses were proposed and research training conducted. Baseline-study interviews were conducted in both the experimental sites where interventions would occur and in the control sites where there would be no specific interventions. A follow-up study was conducted in all sites.

\section{Sampling:}

- Of the fourteen health centers included in the study, eight were experimental and six were control sites selected in Bamako District and the "cercle" of Bla (Ségou);

- 108 service providers were interviewed pre- and post-intervention to evaluate their knowledge, attitudes and practices;

- 5,390 women were observed during their consultations to collect information on the presence and type of FGC and any associated observable complications;

- 1,633 clients were interviewed following their consultations to evaluate the effect any IEC activities had on their attitudes and knowledge.

\section{Prevalence, types of FGC and related complications}

Prevalence. The study was conducted in areas and ethnic groups with high FGC prevalence rates. Ninety-two percent of the clients observed had been cut. FGC type II, which consists of removal of the clitoris and a part of the labia minora, was the most frequently observed (73\%), with type I (clitoridectomy) being found in $21 \%$ of the women. Type III (infibulation), which consists of the removal of the clitoris, labia minora and majora, followed by sewing up of the labia minora, was observed in $6 \%$ of the women. In Mali, involuntary infibulation sometimes occurs when the young girl's legs are tightly bound together after the operation. In Bobo, Dogon, and Senufo/Minianka ethnic groups, Type I was the most prevalent.

Complications during delivery: Many women were observed during delivery. The follow-up of the delivery process led to the observation that normal delivery occurred in a higher proportion of the clients not cut (93\%) than in those who were cut. In fact, tissue tearing was more frequent among circumcised women than others. Episiotomy and hemorrhages were also more frequent among circumcised women (16\%). Among the women who presented for delivery, $29 \%$ of the circumcised women had complications, while only $7 \%$ of noncircumcised women had complications. Multivariate analysis confirmed that the probability of having a difficult delivery significantly increased with FGC.

Other complications: Among the $4 \%$ of women who have been reported to have other types of complications, the primary complications included vaginal stenosis and keloids.

The results demonstrate that complications are directly related to the severity of FGC complications were seen in $3 \%$ of women with type I, $4 \%$ of women with type II and $14 \%$ with type III. 


\section{Service providers' knowledge, attitudes and practice}

The training component of the intervention resulted in a considerable increase in knowledge of FGC among providers. Knowledge that there are at least three types of FGC increased from $17 \%$ to $76 \%$, the knowledge of at least three immediate complications increased from $40 \%$ to $86 \%$, and knowledge of subsequent complications from $49 \%$ to $72 \%$. There was a clear improvement of service providers' understanding of various aspects of the practice, such as the presence of health risks even with removal of the clitoral hood only and in the most hygienic environment. A slight decrease was also noted regarding the bias against uncircumcised girls.

The training also resulted in increased numbers of personnel who are able to detect FGCrelated complications at the time of delivery. The majority of service providers (54\%) had dealt at least once with clients suffering from an immediate complication related to FGC, and $36 \%$ had had to refer a client for further treatment due to complications. They had experience with complications, but also felt that their skills were limited in the management of these cases.

The practice of FGC in the medical setting is real: $13 \%$ of the personnel interviewed admitted that FGC is being practiced in their health facility, while $4 \%$ had actually performed at least one procedure, and $2 \%$ stated that they would continue to practice.

\section{Effect of Intervention}

IEC given in health centers: Training was given to the service providers because of their potential role in the fight against FGC. They were expected to conduct anti-FGC talks with their clients. After the training, the great majority of providers (88\%) thought that campaigns against the practice of FGC should be initiated, and $72 \%$ thought that their role in such campaigns could be awareness-raising. These percentages increased between the pre-test and the post-test. However, one notes a significant change after the intervention. Although the proportion of providers who supported anti-FGC campaigns increased, it seems that the proportion of those who were willing to lead the campaigns decreased. This might be explained by the fact that these health agents, after having received training, would be in charge of implementing IEC activities in their facilities. After returning to their regular service, they recognized the difficulty of leading these activities personally.

An inventory of IEC material was undertaken in each of the study sites. This tool allowed the study coordinators to determine the status and availability of IEC material. Information on the education and counseling sessions were held in the sites for one week.

All experimental sites were supplied with a flip chart, which was developed during the initial stage of this project to facilitate the IEC activities. The great majority (96\%) of the service providers who used the flip chart said that it enabled them to better communicate messages. Among the service providers questioned, $38 \%$ found that the flip chart was not constraining. Among the $63 \%$ who did not agree, $56 \%$ still found it useful, even though it was a constraint. Flip charts were found to be in good condition in all the sites, fact which might be explained by their limited use during counseling sessions. 
The education session was only held in two sites. The majority of service providers who carry out these IEC activities have not received training in communication skills. The only communication technique used during the training session was practical role-playing.

It appears that counseling is practiced more in the rural sites than the urban sites. Half of the service providers who had carried out the IEC activities were at ease when the theme of excision was discussed.

Effect of the intervention on clients: In the post-test, only $9 \%$ of women interviewed had participated in an education session at the time of their visit. FGC was discussed in half of all health talks.

Only $4 \%$ of the clients interviewed had received information on FGC during the study period. The majority of these clients were comfortable with and interested in the subject. Most of the women responded that the explanation given by the service providers during the session was clear and easy to understand. Nearly half of those who had received information on FGC said that they were going to talk to their family and friends. This shows the clients' interest in the issue, especially since we know that $75 \%$ of the population interviewed had no prior knowledge of the health repercussions related to FGC.

Recommendations: Several recommendations were made during the national dissemination seminar. Among these recommendations, the $\mathrm{MOH}$ retained five for immediate action.

- Introduction of training modules on FGC in public health training curriculum

- Training of all active health personnel on FGC by integrating the module into the inservice reproductive health training program

- Development of a strategy for informing youth of the problems associated with FGC.

- A MOH decree forbidding the practice of FGC in health clinics and the proposition of a law banning the practice altogether.

- Undertaking operations research to improve the quality and effectiveness of IEC in health facilities. 


\section{INTRODUCTION}

\section{A. Context}

Mali is a landlocked country with different climate zones: Saharian, Sudanese, GuineanSudanese. According to the 1997 census, 9, 364, 549 people live in Mali, with a population density of 7.2 inhabitants per square kilometer. The density varies between the northern and southern regions and $58 \%$ of the population lives in only $8 \%$ of the territory. The Malian population is around $51 \%$ female, $39 \%$ of which are of child-bearing age. According to the Mali II Demographic and Health Survey (DHS Mali II) report published in 1996, female genital cutting (FGC) affects $94 \%$ of the female population and exists in most parts of the country. FGC is a traditional practice among the ethnic groups in the south (Bambara, Malinke, Sarakole, and Senufo) but concerns only a minority of people living in the north. FGC is not traditionally practiced among the Songhay, the Moors, and the Tuareg. Prevalence rates do not vary much among the three Malian religious groups. Among Muslims, Christians, and animists, more than $75 \%$ of the female population is circumcised. The only factor that seems to affect the prevalence of FGC is the mother's status, whether or not she herself was cut and her level of education (Tokindang and Diallo, 1997).

There are a number of explanations for female circumcision that can be found in anthropological theories. FGC in Mali predates the arrival of Islam. The Mandingo (Bambara, Malinke, Sarakole) justify the practice through wanzo, an evil force acquired at birth which resides in the clitoris. The ablation of the organ rids the girl of the nefarious spirit, increases her fertility and assures the survival of her future offspring. In the Dogon symbolic system, the human being is seen as a double gendered entity: females are part male because of the clitoris and males are part female because of the prepuce. These need to be cut to insure stability. Removing the clitoris rids the girl of her masculinity and, by offering her blood, she is relieved of her debt to the earth. Most Songhay do not practice FGC. The ethnic groups that cut their girls often say this is related to the discovery of fire. Fire was originally given to women and, so that it would not be extinguished, women must be purified by removing their clitoris. These explanations drawn from traditional symbolic systems are those most cited by women, although some also evoke religious reasons.

In Malian society other reasons are also given. From a sociological point of view, a noncircumcised woman may be ridiculed by her co-wives or repudiated by her husband. From a hygienic and esthetic point of view, the external female genitalia are seen as dirty and ugly. And from a psycho-sexual point of view, FGC diminishes the woman's libido and keeps her faithful.

In 1980 the Union Nationale des Femmes du Mali began campaigning against FGC (Baumgartner et al). Several local NGOs have also been involved in the struggle against the practice and have used a strategy targeting the traditional circumcisers. This consisted of 1) 
efforts to convince the circumcisers to "lay down the knife;" 2) financing of alternative income-generating activities.

The ASDAP focused their program on IEC activities to raise awareness in the communities of Koulikoro and Segou. For example, they set up regular meetings with the circumcisers, with health care providers, and with local organizations and community leaders in order to exchange information and opinions regarding FGC, the prevalence of the practice, the possible health consequences, and the changes that had occurred in the practice. An effort was made to convince the circumcisers to become "agents of change," to participate in organized discussions, to make home visits, and to advocate for change with local decision makers. A third component of the program provided financial assistance or loans to help the circumciser to start alternative activities. This last method proved, however, a financial burden for the NGO, and it demands regular monitoring.

Other organizations such as CADEF, the AGM, and the Centre Djoliba focus especially on human rights, emphasizing the damage inflicted on the woman's bodily integrity by FGC. COFESFA and AFEM, whose primary program focus areas are women's reproductive rights, literacy, and environmental hygiene, have also contributed to raising the population's awareness of the dangers of FGC.

The national committee in the fight against traditional practices (COPRAMAT), which is composed of governmental institutions, the Red Cross, and the Djoliba center, have also contributed to the movement.

On the government level, the Commissariat à la Promotion Féminine (CPF) and the Direction de la Santé Familiale et Communautaire (DSFC) have defined FGC as an intervention issue central to women's empowerment. Governmental support to the movement to reduce FGC has taken the form of a national action committee (CNA) which seeks to eradicate all practices that put the health of women and children at risk.

When the CPF became the Ministry for Women, Children, and Families in September 1997, a national plan to abandon FGC by the year 2008 was designed. It consists of two four-year stages. The goal of the first stage (1999-2003) is to reduce FGC in Mali by $40 \%$. The program will cover the whole country.

Bills which would have made the practice of FGC illegal were not adopted by the National Assembly. Citing the case of Sudan where coercive measures appear to have provoked resistance and an increase in the practice, the legislators thought it best to proceed cautiously.

\section{B. Justification of this study}

In light of the harmful effects FGC can have on the health of women and girls, interventions aimed at the eradication of the practice have been conducted for many years (Toubia: 1995). Recently, the international conferences in Cairo and Beijing have condemned the 
practice as a violation of women's rights and proclaimed women and girls should not be subjected to the unnecessary suffering and mutilation of FGC. The practice is also a priority issue for WHO which has undertaken an extensive research and analysis of consequences of FGC and the appropriate ways to intervene.

Efforts to reduce FGC in Mali have been geared toward sensitizing population subgroups such as women and opinion leaders. However after two decades of anti-FGC campaigning, it is time to recognize that the results are not satisfactory when compared with the human and financial investment. Other approaches need to be found.

One approach is to use health personnel in the struggle. Health care providers are routinely in contact with people of all social levels and have the opportunity to discuss the health consequences of FGC. Clinicians are frequently called to identify and treat FGC-related health complications. Health personnel constitute an important resource that has not been fully used.

Following the resolutions of the 47th general assembly devoted to FGC, WHO recommended that all health personnel be involved in raising awareness in the population in order to eradicate FGC. Additionally, WHO has firmly condemned "the medicalization of all forms of female genital mutilation in whatever circumstances, in hospitals or other health centers".

The situation in Mali is as follows:

- There is a progressive medicalization of FGC to satisfy the demands of parents who, hoping to avoid accidents or future health complications, bring their daughters to health centers to be cut. The results of the Mali II DHS survey showed that while only $2 \%$ of women interviewed had undergone FGC in health facilities, $5 \%$ of elder daughters had. Although this is not a significant increase, it does indicate a tendency toward the medicalization of the practice.

- The daughters of health professionals are just as likely to undergo FGC as other girls in Mali.

- Social and health personnel have barely begun to get involved in the fight against FGC. Health facilities rarely offer IEC sessions on the subject.

- Health complications due to FGC and specific care needed to treat patients with these complications are not covered in the training curriculum of social and health agents.

All of these facts motivated the start of this pilot research the results of which should improve the providers' knowledge of FGC and their ability to contribute in the struggle against the practice. 


\section{Institutional framework}

To implement this study, a pilot committee composed of the research personnel, national experts from the ASDAP, the Division of Family and Community Health, and the Bamako and Segou regional offices of public health was set up.

\section{OBJECTIVES AND HYPOTHESES}

\section{A. Objectives}

The long term objective of this study is to contribute to the reduction of FGC in Mali through the use of clinical personnel trained in FGC issues.

There were five short-term objectives:

1. Increase the level of knowledge of FGC issues and improve attitudes of health providers regarding FGC-related health problems

2. Reduce the number of clinicians willing to perform FGC at the demand of the parents

3. Increase the number of health-facility clients who are informed of the immediate and long-term health risks of FGC

4. Build the capacities of health personnel in the identification and treatment of FGCrelated problems

5. Collect information on the prevalence of different types of FGC and related health problems among the women who visit health facilities

\section{B. Hypotheses}

Hypothesis 1: Health care providers who have been trained in FGC issues will be better informed of health-related problems and more likely to oppose the practice than those who have not been trained.

Hypothesis 2: Health care providers who have been trained are less likely to agree to cut girls than those who have not.

Hypothesis 3: Clients visiting facilities where the personnel have been trained in IEC techniques to combat FGC are more likely to be exposed to anti-FGC messages and to be aware of the related health problems than those who visit clinics where the personnel have not been trained. 
Hypothesis 4: Health care providers who have been trained will be more able to identify and to treat health problems related to FGC than those who have not.

\section{METHODOLOGY}

\section{A. Research process}

This pilot study began with an observation/evaluation baseline study and ended with an observation/evaluation follow-up study in experimental sites where interventions had taken place and in control sites where there had been no interventions. Interventions took place over two months.

\section{B. Activities}

There were three stages to the study: pre-intervention, interventions, and post-intervention.

\section{Pre-intervention}

This consisted of the four following activities.

1. Recruiting personnel for the study: A consultant in FGC intervention, a researcher form ASDAP, two consultants recruited to coordinate and assist the research, and two members of the national public health office of Mali.

2. Workshop with health and communication specialists: The workshop took place in May 1998 and included two OB-GYN specialists and one communication expert responsible for designing the trainer training workshops.

3. Training workshops: Two workshops were held in June. The participants included eight doctors and two mid-wives from DSFC (division of family and community health), the public health offices in Bamako and Segou and ASDAP, as well as the coordinator and research assistant. Conducted by experts, the workshop covered a recall of female genital anatomy, the practice of FGC (definition, reasons why it occurs, types and complications), the development of a training module for health agents to be used in the experimental sites, and the programming of this training.

4. The use of IEC tools: The Centre National d'Information, d'Education et de Communication pour la Santé had developed visual aids on FGC issues that had been pretested with clinicians and clients. These were explored for use in the test sites.

\section{Interventions}

This consisted of the two following activities.

1. Training sessions with social/health personnel conducted by trainers drawn from a pool of two or three facilitators: Three sessions were facilitated in Bamako and Bla. 
The training consisted of a recall of female anatomy and FGC, its context and local rationale, its prevalence in Mali and elsewhere, and the different types of cutting. The health complications and their treatment was emphasized. An entire day was devoted to the use of visual aids. Role playing was used to simulate counseling sessions. All were trained in filling out health cards.

2. Supervision: The interventions in the test sites were regularly supervised by representatives from the organizations directing the research: DSFC, DRSP, and ASDAP. This allowed for monitoring of the intervention activities and filling out the health cards.

\section{Post-intervention}

During this stage the following activities were conducted simultaneously:

- Interviews with the clinical personnel of the experimental sites having received training and with the control groups contacted during the baseline study

- Observation of the IEC activities to verify that talks were held and the providers did counseling

- Interviews with the clients following their consultations to estimate the information retained.

\section{Sampling and development of data collection tools}

\section{Selection of sites}

The research concerned social/health facilities in the districts of Bamako and Bla (Segou region). The following criteria prevailed in the site selection:

- High prevalence of FGC

- Concentration of health service facilities and OB-GYN specialists

- Capacity of health facilities to collect clinical data

- Lack of prior experience in FGC sensitization activities

- Balanced representation of the various levels of the national health system

Fourteen representative health service points were selected in Bamako and Bla: the Gabriel Toure hospital, referral centers in neighborhoods of Bamako and Bla, clinics in Communes VI (Sogoniko) and II (Missira), community health centers in Bakodjikoroni, Sabalibougou, Fani, and Bogoni, as well as district health centers in Falo, Yangasso, and Diaramana. 
Table 1: Social/health services facilities of this study according to location

\begin{tabular}{|l|c|c|}
\hline Type of health facility & Number in Bamako & Number in Bla \\
\hline Hôpital Gabriel Touré (HGT) & 1 & 0 \\
\hline Centre de Santé de Commune/Cercle (CSC) & 2 & 1 \\
\hline Centre de Santé de Référence & 1 & 3 \\
\hline Centre de Santé d'Arrondissement Revitalisé (CSAR) & 0 & 2 \\
\hline Centre de Santé Communautaire (CSCOM) & 4 & 6 \\
\hline TOTAL & 8 & \\
\hline
\end{tabular}

\section{Selection of health care providers}

The objective of the training was to involve a maximum of health care personnel from different facilities in hopes of their continuing FGC awareness activities after the interventions. Time and other limiting elements in the field forced us to reduce the number of personnel who could be involved. In most clinics, the interventions focused on OB-GYN practitioners since these are the most likely to encounter FGC-related health problems. The health personnel in the six control sites were included for comparative purposes. The sample was comprised of a total of 108 health agents.

\section{Selection of clients}

Clients observed: To establish a profile of FGC practices in Mali and to document any complications, women who visited the eight intervention sites were observed over three months. This concerned particularly women who underwent OB-GYN examinations. Health agents who had been trained in collecting information filled out a health card for each client.

Clients interviewed: Women who had visited OB-GYN or family planning services during the follow-up study were interviewed. One out of five consultations was observed to determine if the women had received counseling on FGC.

\section{Data collection tools}

Four types of questionnaires were designed for this study.

- Interviews with providers: Questionnaire concerning the FGC knowledge of and attitudes toward FGC in the medical context, as well as the socio-demographic profiles of the providers 
- Client health cards: Information on the socio-demographic profiles of the clients, their motives for the clinical visit, their FGC status, any eventual complications, and the delivery process if clients had come to the clinic to give birth

- Inventory guide of clinic: Inventory sheets of the personnel and any IEC material available in the health facility, as well as forms for the monitor to complete on IEC activities that had been conducted

- Interviews with clients: Questionnaire translated into local languages administered to clients in experimental and control sites to evaluate the impact of the health-care agents' training

\section{Data collection}

A baseline study was conducted at each test-group and control-group site. Health care providers filled out an auto-evaluation form or were interviewed regarding their knowledge of FGC issues.

The data collection in test sites was gathered over three months at regular intervals.

For the follow-up study, five field interviewers were recruited to conduct interviews with outgoing clients and to check the inventories. These interviewers had followed a four-day training on FGC, counseling, and interviewing and observation techniques. The interviews took place over one week in each field site.

\section{E. Data treatment and analysis}

Data was entered and treated using EPI-INFO and SPSS 7.5. software programs. A descriptive analysis, tests for meaning, and a multivariate analysis were carried out.

\section{F. Limits of this study}

As in all research projects, this study met with certain limits.

Limits of sampling: The ideal case would have been to train all health agents in the test sites. This, however, was not possible because of material constraints. Thus the coverage is less than desired.

\section{Methodological limits:}

1) Some questions were not fully explored. Between 20 and 65 of the health agents in the follow-up study sites did not respond to questions relative to their IEC activities. 
2) Among those who had participated in the baseline study, four were not present during the follow-up study and could not be interviewed. This explains the discrepancy of the respondent numbers between the starting and ending stages.

3) Time constraints at the start delayed the final data collection stage until the rainy season. Fewer clients could be interviewed since, particularly in rural areas, women visit health facilities less frequently than in the dry season.

Limits of analysis: Our third hypothesis - that clients visiting health centers where the personnel had been sensitized and trained in IEC techniques were more likely to hear antiFGC messages and become aware of the health risks-could not be verified because of the low number of women who were exposed to IEC activities in the experimental sites.

\section{DISSEMINATION AND USE OF RESULTS}

The results were shared during the following events.

- An interpretation workshop: This two-day workshop gathered together the pilot committee and diverse agents specialized in FGC issues. The findings have contributed to the enrichment of the analysis and the relevant bibliography, and has also produced concrete recommendations.

- A national symposium: Eighty people including those mentioned above, development partners, members of NGOs involved in the anti-FGC campaign, health personnel from the study sites, and members of the press participated in this symposium.

- Further dissemination: The results are to be shared in sessions gathering health agents from OB-GYN services and the directors of medical-training schools in Mali during the year 1999. The $\mathrm{MOH}$ intends to broadcast the results in their fields of operation, particularly at the regional level.

- International OR/TA conferences: The preliminary results have been presented at conferences in Nairobi, Dakar, and Washington DC occurring between September and November 1998.

\section{Actions being taken following this study include:}

- The Ministry of Health has integrated a module on FGC in their reproductive health training curriculum.

- The ASDAP has also integrated the module in their programs directed toward youths.

- Health professionals have expressed a strong interest in having the picture flip charts made available to health services. A demand for their reproduction was addressed to the organizations involved in this study. 
- The Minister of Health has personally committed to issuing a ministerial order forbidding FGC in all medical sites.

\section{PRESENTATION OF MAIN RESULTS AND RECOMMENDATIONS}

\section{A. Presentation of sampling}

\section{Clinical sites}

The fourteen study sites were chosen by regional directors in accordance with the policy of health service facilities in Mali. All levels of the national health system were represented in the types of study sites selected: One hospital (HGT), urban commune health centers (CSC), referral centers, improved district health centers (CSAR), and community health centers (CSCOM).

Table 2: Health facilities in control and test sites

\begin{tabular}{|l|c|c|}
\hline Type of health facility & Control site & Test site \\
\hline Hôpital Gabriel Touré (HGT) & 0 & 1 \\
\hline Centre de Santé de Commune/Cercle (CSC) & 1 & 1 \\
\hline Centre de Santé de Référence & 0 & 2 \\
\hline Centre de Santé d'Arrondissement Revitalisé (CSAR) & 2 & 1 \\
\hline Centre de Santé Communautaire (CSCOM) & 3 & 3 \\
\hline TOTAL & 6 & 8 \\
\hline
\end{tabular}

\section{Health care providers}

Out of 108 providers contacted for the baseline study, 59 worked in test sites where training activities were conducted and 49 in control sites where no training was conducted. The subjects were selected among OB-GYN and Family Planning providers, including doctors, certified nurses and nurses-in-training or nurse aides, mid-wives and traditional birth attendants (TBA), and health technicians.

The median age of these practitioners was 38 years. The youngest was 18 and the oldest 52 years old. The majority of the providers ( $82 \%$ ) had been or were married. Of these, $44 \%$ were monogamous, $33 \%$ polygamous, and around $7 \%$ were widowed or divorced.

All ethnic groups are represented in the provider sampling, but the Bambara at $34 \%$ were the majority group. In regards to religion, $96 \%$ declared they were Muslim. 


\section{Clients}

Clients observed: Over a given period, all the OB-GYN and family planning consultations of clients who came to the test sites were observed. Data on the types of FGC found, on eventual complications, on reproductive history, and socio-demographic characteristics were registered on health cards.

Thus, all information relating to FGC was collected from 5,390 women. Because of the higher volume of patients in urban health centers, the number of clients observed there is four times higher than in rural centers. Of the total observed, $79 \%$ were in Bamako and $20 \%$ in Bla (Segou region).

Although all Malian ethnic groups were represented in the sampling, the Bambara dominated at $41 \%$ (see Graph 1). The average age of clients was 27 and $50 \%$ were under 24. Eighty-seven percent of the clients had been married and $2 / 3$ rds were living in a monogamous household. The average number of deliveries was three and the number of live births around two children.

\section{Graph 1: Ethnic distribution of clients observed}

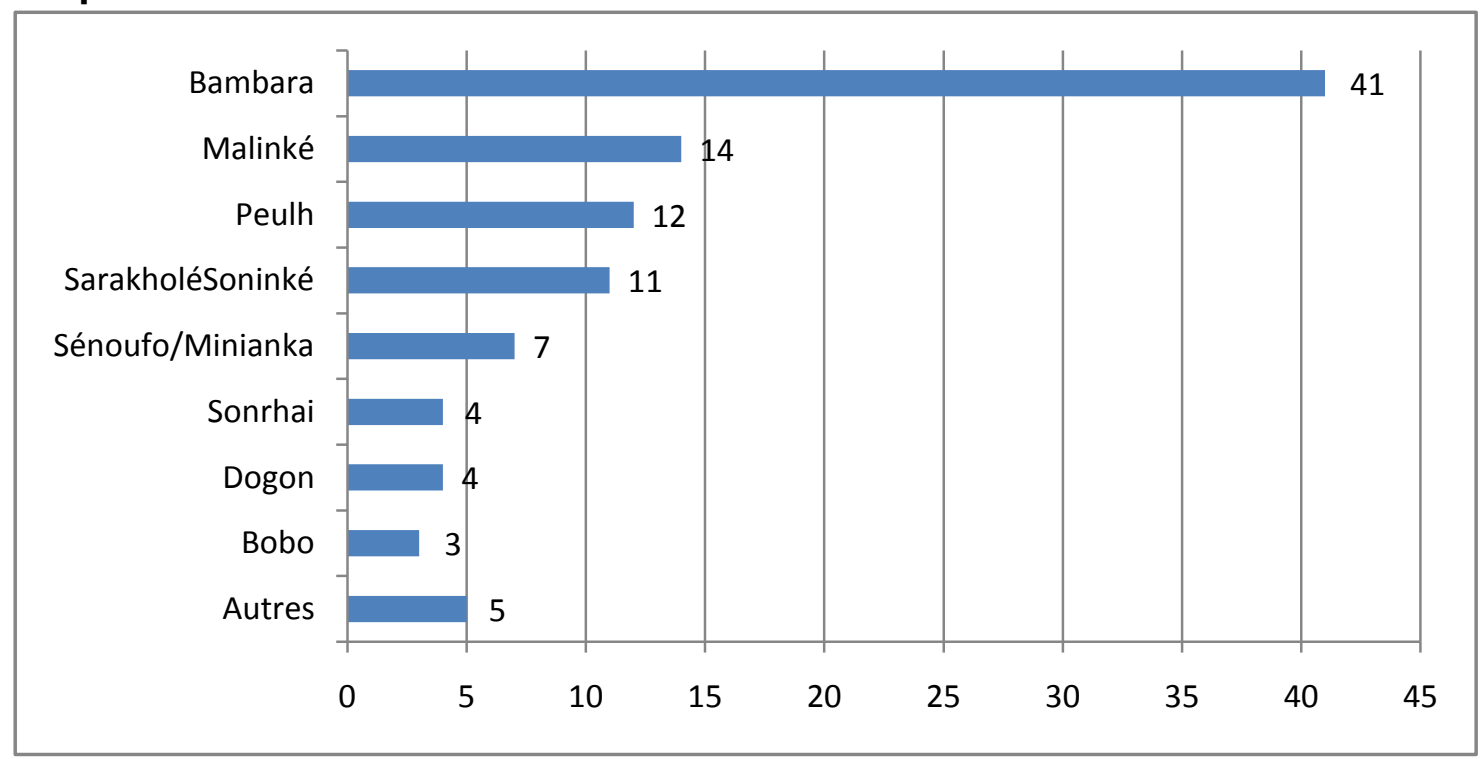

\section{Source: Client observations $n=5,326$}

Clients interviewed: All clients visiting the designated sites during the final stage of the study were interviewed after their consultations. Thus, 1,633 women responded to questions concerning the services they had received.

The median age of clients interviewed in the test sites was 19 years. Eighty-seven percent were married, $2 / 3$ rds of whom were in a monogamous relationship. At $45 \%$, the majority of clients interviewed were Bambara. Three/fourths live in urban centers. Ninety-five percent are Muslim. 
Clients in the control sites displayed similar characteristics. Their median age was between 17 and 18 years. About $87 \%$ were in marital relationships, $63 \%$ of which were monogamous. Forty-two percent of these respondents are Bambara and $54 \%$ live in urban centers. They are $96 \%$ Muslim.

The fertility rate of clients interviewed in both the experimental and the control sites is similar. The average age of the first birth delivery is 18 years, the number of surviving children is three, and the number of deliveries is four. The maximum number of birth deliveries among the women interviewed was one client who registered 15 deliveries. Clients interviewed in the test sites had an average of one daughter and $71 \%$ declared that she was circumcised.

\section{B. FGC profile in Mali}

\section{Prevalence rates of different FGC types}

Of the clients observed, $92 \%$ had undergone FGC. The majority of the ethnic groups represented in the study practice FGC.

In rural contexts, the data collected concerning daughters indicated that the FGC prevalence rate of girls between the ages of 0 and four years was $35 \%$. The prevalence rate for girls between the ages of five and nine years was $75 \%$. This indicates a tendency, even in rural contexts, of girls being cut early in their life.

\section{Graph 2: Distribution of circumcised clients by FGC type}

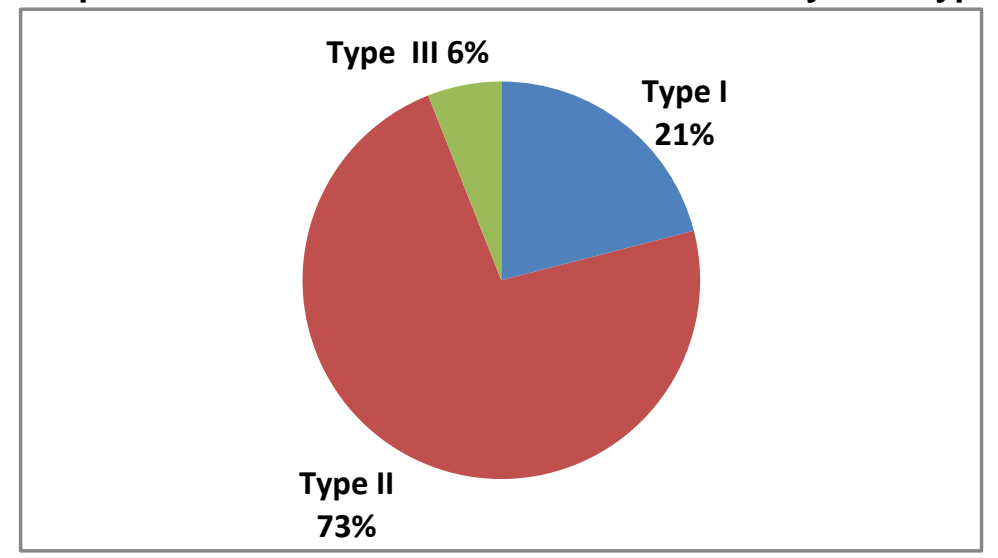

Source: Clients observed $n=4847$
Among the women themselves, type II FGC, which consists in the ablation of the clitoris and the labia minora, was the type most often observed. Infibulation or type III, which consists in the removal of the clitoris, the labia minora, the labia majora with stitching of the labia was found among $7 \%$ of the respondents. (See Graph 2)

The percentages of girls undergoing the three types of FGC vary according to ethnicity. Type I is the most prevalent among the Bobo, Dogon, and Senufo. It must be noted that type III or infibulation is not always the fact of the wound being deliberately stitched closed, but often occurs as a result of the girls being told to hold their legs together tightly after the cutting, which results in an involuntary sealing and scarification of the tissues. (See Graph 3) 


\section{Graph 3: Distribution of clients observed by FGC type and ethnicity}

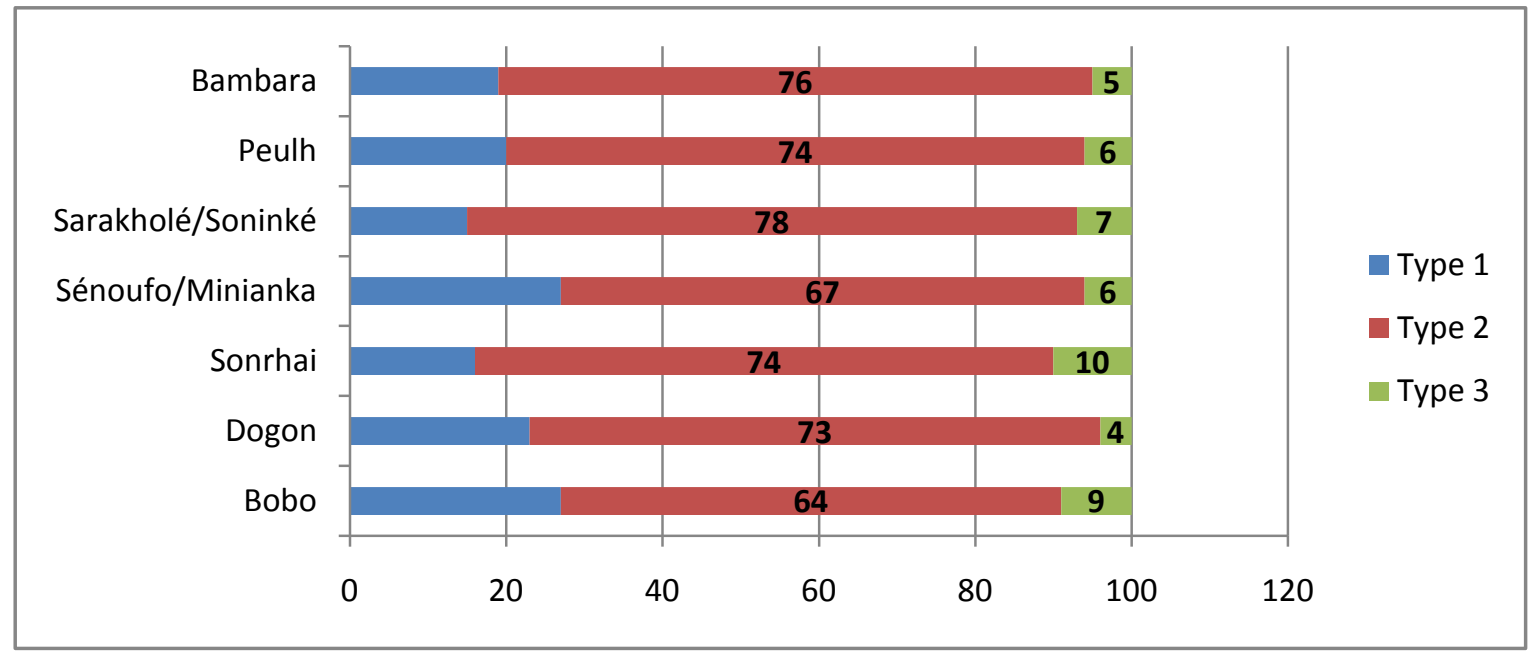

Source: Observation $\mathbf{n}=$ variables

\section{FGC-related health complications}

\section{Birth delivery complications}

A considerable number of women in labor were observed. The number of normal deliveries among non-circumcised women (93\%) is higher than among those who have been circumcised. Cases of tearing, episiotomies, and hemorrhages were more frequent (16\%). Among women who came to deliver at the study sites, $29 \%$ of those who had been circumcised experienced problems versus only $7 \%$ of those who had not been circumcised. (See Graph 4)

A multivariate analysis confirmed that the probability of delivery complications is significantly higher among women who have undergone FGC.

\section{Other complications}

Among the clients observed, $4 \%$ of other FGC-related health problems were reported. These included vaginal stenosis (8\%), keloid inflammation (7\%), and abnormal bleeding (61\%).

The study shows that the more severe the FGC, the more complications are likely to occur: among women having undergone type I, $3 \%$ of the complications occurred; among those of type II, $4 \%$ occurred; among those of type III, $14 \%$ occurred. 


\section{Graph 4: Complications at delivery according to FGC status}

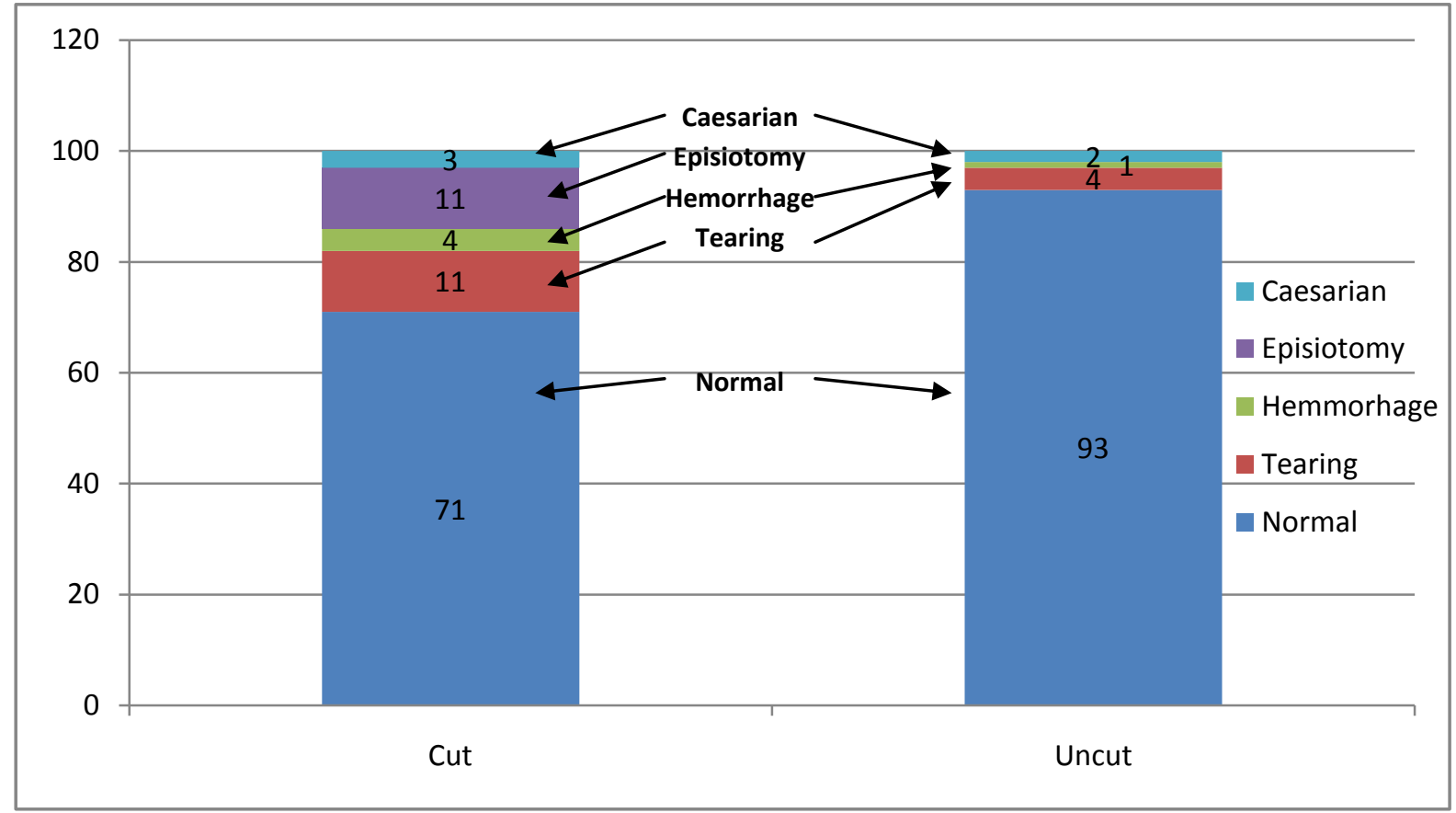

Source: Clients observed $\mathrm{n}=\mathbf{2 0 8 7}$

\section{Complications reported by clients who were interviewed}

Women visiting the fourteen health facilities included in this study were interviewed after their consultations. A series of questions relating to FGC revealed a number of consequences attributed to the practice.

\section{Physical consequences}

Twenty-five percent of the respondents declared they had personally experienced or witnessed FGC-related complications. Twelve percent said they knew of cases in their environment, $10 \%$ said they had seen cases in their immediate family, and $3 \%$ said they had themselves experienced complications. The health consequences most frequently cited were difficult deliveries, vaginal occlusion, tearing, hemorrhaging, urinary retention and incontinence, hematoclopos, and death.

Near $38 \%$ of respondents said they had experienced delivery complications which could be attributed to their circumcision. Twenty-five percent had experienced tearing of the perineum and episiotomies, $7 \%$ had experienced hemorrhaging, 15\% had undergone a caesarian, and the majority (54\%) had experienced a difficult delivery.

Comparing results between respondents who had undergone FGC and those who had not reveals that $24 \%$ of circumcised women report tearing or an episiotomy as compared to only $9 \%$ of uncircumcised women. 


\section{Consequences affecting the couple's relationship}

Although the great majority of respondents declared that they had not been psychologically affected by their circumcision, $4 \%$ declared they did have psychological problems.

About half of the clients interviewed said FGC in no way affected their married life. Fortytwo percent did not recognize any link between FGC and marital problems. Only 8\% declared this might have affected their life in a couple. Those who agreed to talk about this subject said sexual intercourse could be painful. In some cases, the consummation of the marriage involves an incision or forced penetration because of sealed tissues. This initial experience frequently marks the woman's married life and leads to a dread or disgust of sexual relationships.

Respondents also mentioned that men preferred to marry circumcised women and that a woman who is not cut can be repudiated. In polygamous families, the presence of a noncircumcised woman can become a source of on-going conflict. Thus, some married women ask to be cut in order to conform to their social context. However, a few women mentioned that since FGC sometimes leads to sterility and that the major purpose of marriage is propagation, the sterile woman can be divorced.

\section{General conclusions and recommendations regarding FGC cases}

* FGC remains widespread in Mali. Type II is the most frequently observed. Although other types are rarer, any campaign to eradicate the practice should include all types.

* Reliable data gathered among health care professionals shows the kinds of health complications caused by FGC. The FGC modules should emphasize the risks in prenatal health consultations so that these might be better avoided or treated during birth delivery.

\section{Health service providers}

\section{FGC knowledge among health service providers}

\section{Health agents' knowledge of FGC types}

There was a noteworthy increase between the baseline and the follow-up studies. Among the sensitized agents, the proportion which did not recognize the different types of FGC in the baseline study $(24 \%)$ decreased to only $5 \%$. Knowledge of at least three types of FGC increased from $17 \%$ to $76 \%$.

One must recognize that in the control sites where no IEC activities had been conducted, knowledge of FGC also evolved between the time of the baseline and the follow-up studies. The percentage of providers declaring they had no knowledge of FGC types dropped from $53 \%$ to $19 \%$ who could cite one to two types. This improvement can be explained by the fact that, even though these health agents had not followed IEC training, they had been 
sensitized during the initial stage of the study and might have sought out information on their own.

\section{Knowledge of FGC immediate and long term complications}

The great majority of health agents interviewed during the baseline study knew that complications could arise immediately after the cutting. The proportion of agents in the experimental sites who could name at least three FGC types almost doubled between the baseline study and the follow-up study, passing from $40 \%$ to $86 \%$. Immediate FGC complications most frequently cited were hemorrhaging and death.

There was also a greater awareness of FGC long-term complications. The proportions went from $50 \%$ to $72 \%$ awareness of at least three possible health problems related to FGC. Most often cited were difficult deliveries, infections, and death. (See Graph 5)

\section{Graph 5: Knowledge of long-term FGC complications among providers in test sites}

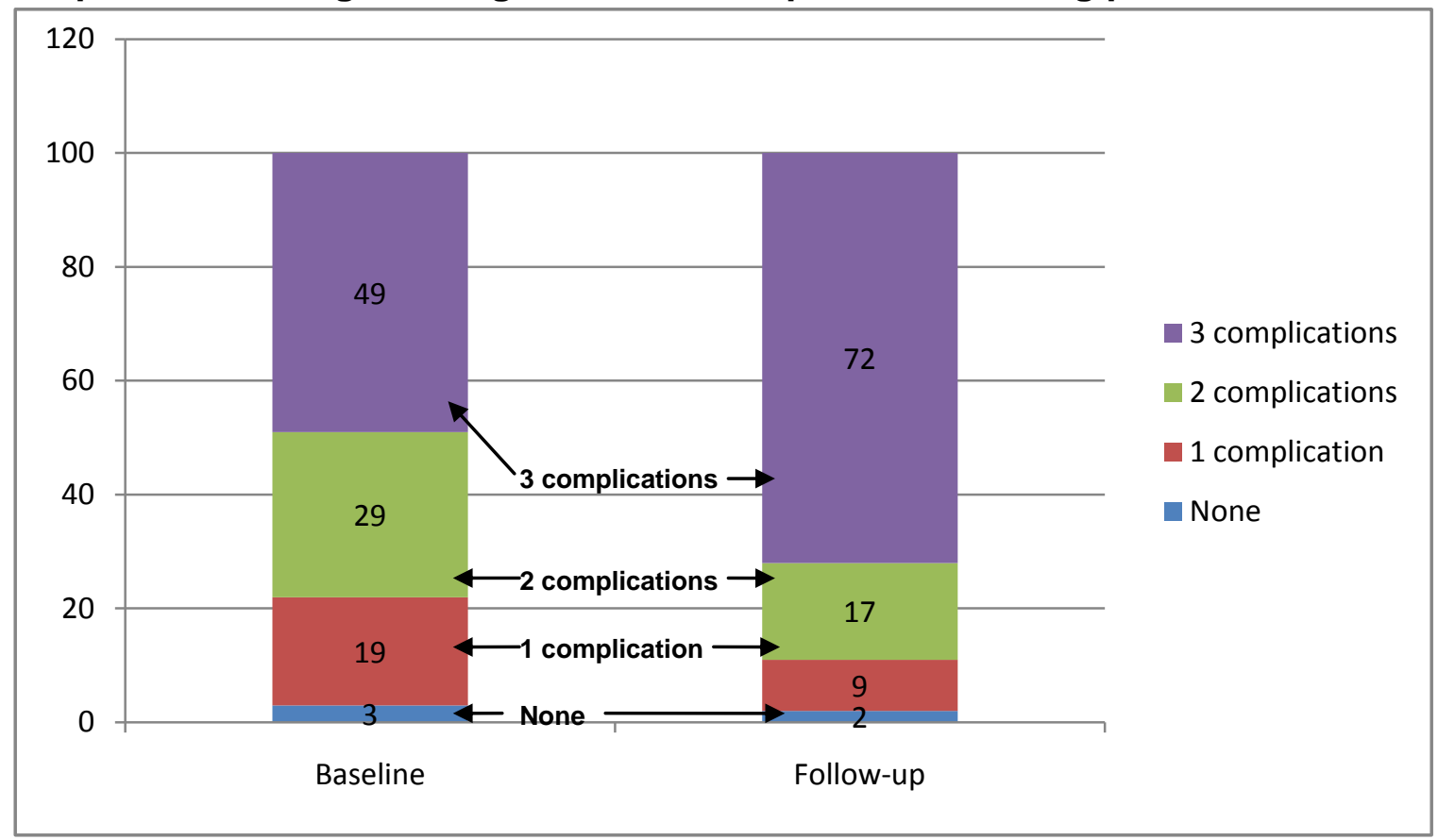

\section{Source: Provider interviews $\mathrm{n}=58$}

Sixty-three percent of health care providers interviewed thought that FGC has an impact on the health of the mother and the child. Reasons given ranged from fistula of the genitalia and the rectum to hemorrhaging and severe damage or death to the fetus.

To a lesser degree, respondents from the control study sites also registered improvement in their knowledge of FGC complications. The total of $61 \%$ aware of possible consequences during the baseline study went to $73 \%$ in the follow-up study. However, one must note that, although providers in the control sites who were interviewed were likely to seek out more information, they did not receive complete training. One cannot necessarily conclude that knowledge of the long-term effects of FGC increased in the control groups. 


\section{Health service providers' experience with FGC complications}

Fifty-four percent of providers declared they were confronted with FGC health complications at some point in their practice; $36 \%$ had to refer such cases to other clinics. The health agents indicated they had little training in such cases. (See Graph 6)

Graph 6: Immediate and delayed FGC-related consequences encountered by providers

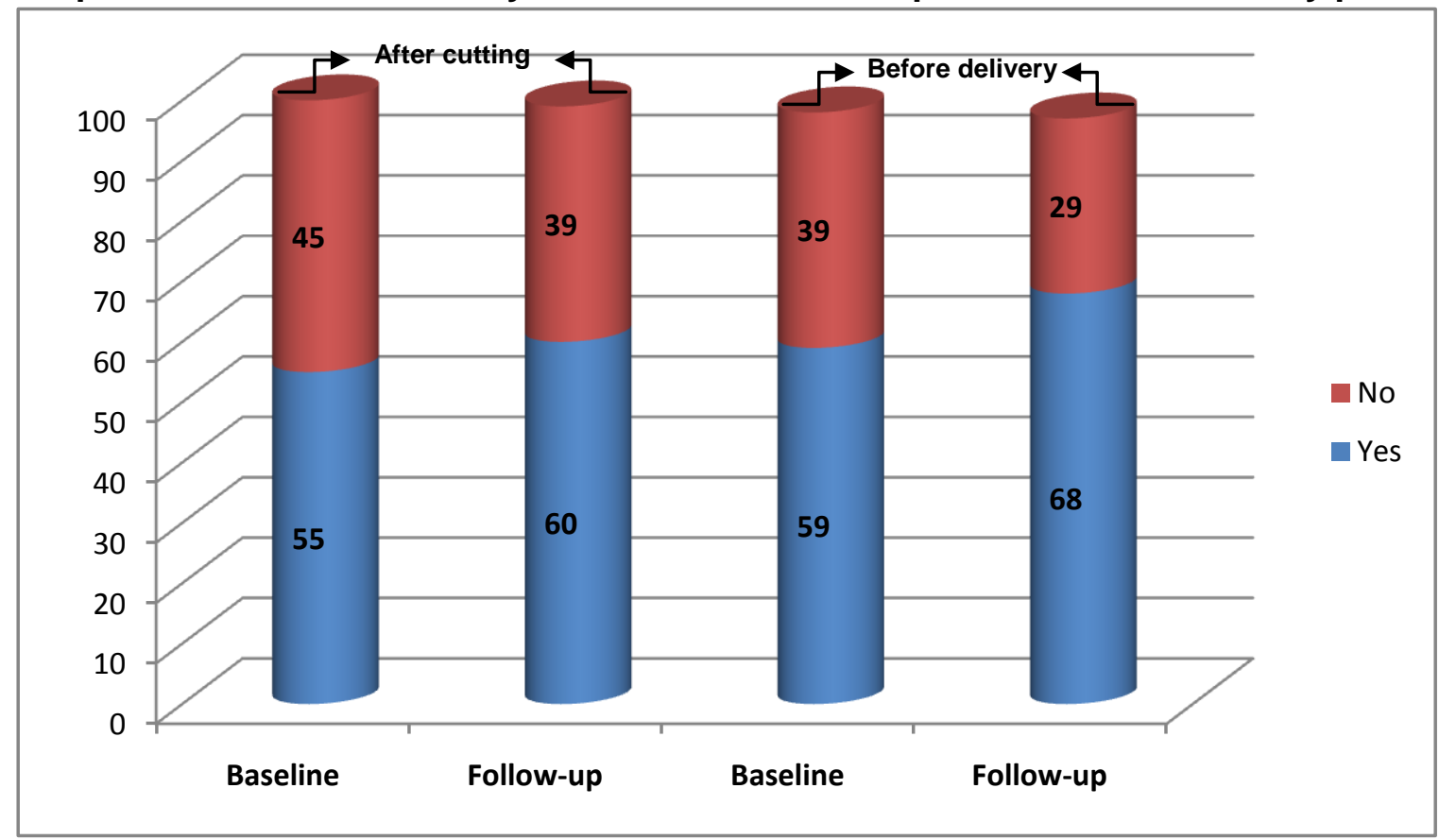

\section{Source: Providers interviewed $\mathrm{n}=108$}

\section{Providers' attitudes toward FGC}

This research sought to discover the opinions of health care providers regarding explanations of the practice of female circumcision common in Malian society.

The great majority (84\%) of the providers interviewed thought that a tradition or a belief can change or be abandoned and that some of these are good and others not. Men seemed slightly more open to change than women did. Almost all thought that traditions that had a negative impact on health should be abandoned. Nevertheless, $10 \%$ considered a tradition to be by definition immutable.

Over half (59\%) of the providers interviewed for the baseline study thought that "female genital mutilation" was an appropriate term to describe the practice. The others found the term abusive $(6 \%)$, exaggerated $(17 \%)$, or inappropriate $(17 \%)$. These percentages did not shift significantly between the baseline and the follow-up studies.

An argument frequently used to maintain FGC is that this keeps the sexuality of girls and women under control. Graph 7 shows providers' opinions on whether girls who have not undergone FGC have "loose morals." 
Graph 7: Providers' opinions on whether uncircumcised girls have loose morals

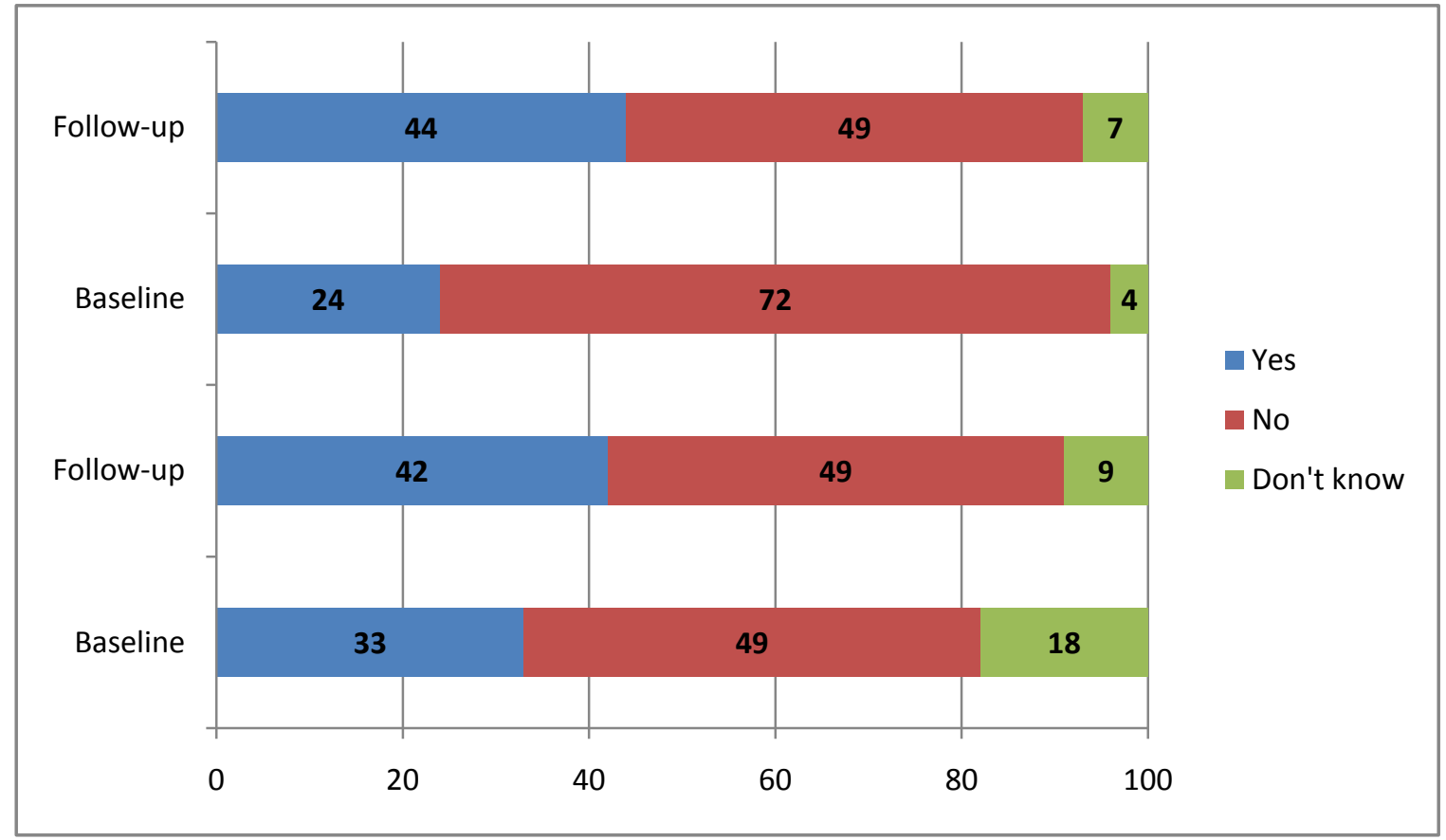

Source: Providers interviewed $n=108$

Health personnel's opinions on this subject did not differ greatly from the general population. Thirty-nine percent found that uncut females tend to have "loose morals." However, this proportion did decrease to $26 \%$ in the follow-up study.

In regards to the widely held opinion that men prefer to marry circumcised women, the number of health agents interviewed who agreed dropped from $32 \%$ to $28 \%$. Those who thought FGC guaranteed virginity until marriage dropped from $14 \%$ to $9 \%$.

\section{Providers' opinions on FGC and health}

Seventeen percent of health personnel interviewed during the follow-up study thought that FGC posed no health risks if done in a hygienic environment versus $35 \%$ in the baseline study (see Graph 8). In spite of the decrease, a large number of health practitioners continue to think FGC is safe if done in a health facility. 
Graph 8 : Providers who think FGC does not pose a health risk if performed in a hygienic environment

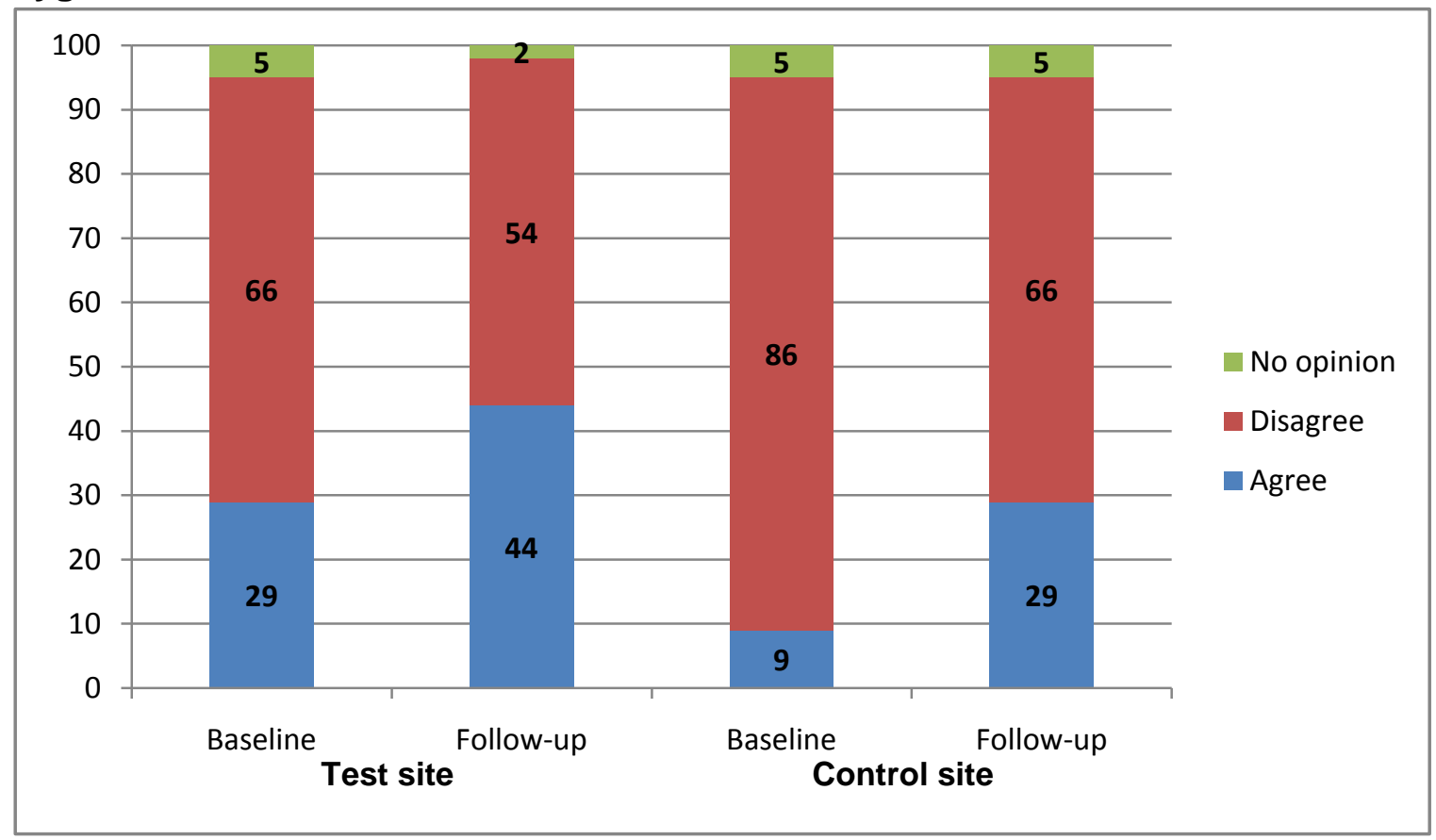

\section{Respondents test sites $n=58 \quad$ Respondents control sites $n=48$}

In the final evaluation in both the test sites and the control sites, around $30 \%$ of the providers thought that the removal of the clitoris hood did not constitute a health risk for the girl. This proportion shows a slight decrease since the baseline findings before the training.

Almost 55\% in the baseline interviews and $77 \%$ in the follow-up interviews thought that FGC could cause sterility.

\section{Medicalization of FGC}

In Mali there has been a tendency in recent years toward having girls cut in health facilities or by a health care provider. At the start of the anti-FGC campaign in the 1970s, national associations and NGOs made recommendations which opened the practice to the medical field. The idea was to pursue the practice of a more moderate FGC practice (Type I) in a sterile environment in order to reduce the health risks. To this purpose, there were also training sessions organized with traditional practitioners to improve the hygienic conditions of the operation and provide appropriate instruments. Undoubtedly, these strategies contributed to the medicalization of FGC.

The data displayed in Graph 9 show that, while 62 out of 107 of these respondents believe FGC should be forbidden, four have practiced FGC in a medical context. These were three mid-wives and one TBA whose ages were between 35 and 54 years. Two said they would be willing to perform FGC again. Paradoxically, all said the practice should be abandoned. 


\section{Graph 9: Medicalization of FGC in Mali}

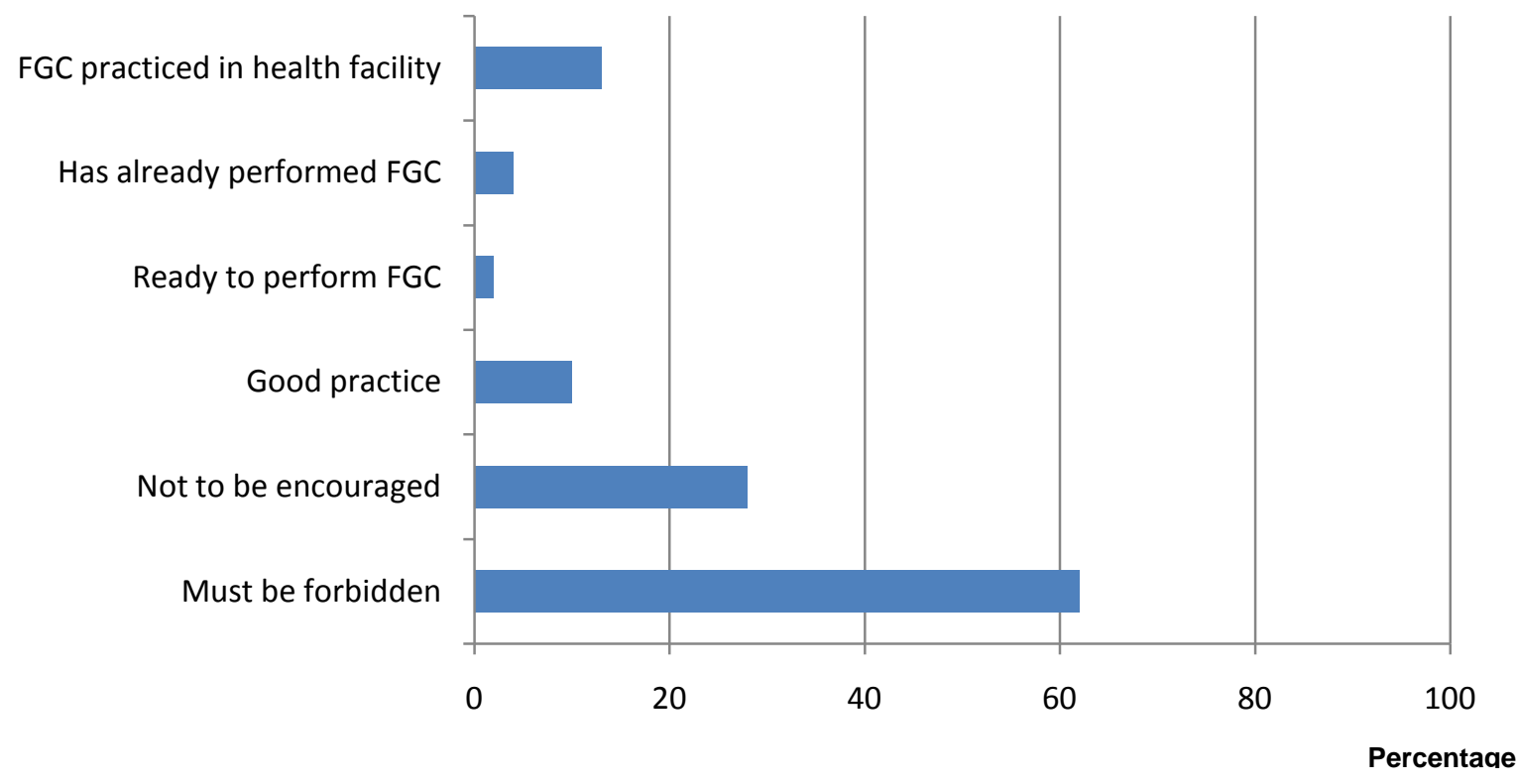

Source: Provider interviews $\mathrm{n}=107$

Data distributed according to the type of facility show that the great majority of health care personnel thought that FGC should be forbidden in the medical context. Most of those who favored continuing the practice in health facilities were found in community health centers. In the CSCOMs, $70 \%$ of the agents, whatever their age, thought that FGC practiced in a hygienic environment reduced health risks.

The study shows that to date FGC is still practiced in medical contexts; $13 \%$ thought it was practiced in their facility. The question of whether mid-wives who had retired would return to the health facility to operate remains open. It is obvious that anyone continuing to practice FGC is not likely to frankly admit to that. One has to look beyond the data gathered in these interviews to determine how widespread the medicalization of FGC is in Mali.

\section{Conclusions and recommendations regarding health care providers}

* The training allowed capacity building among the providers. Between the initial and final stages of this pilot study, knowledge of at least three FGC types increased as well as knowledge of the immediate and long-term consequences of FGC. All social and health personnel at all levels of the system should be trained in FGC-related issues.

* For a sustainable impact, the FGC module should be incorporated not only in periodic recycling training programs, but in the basic curriculum of public health schools.

* The practice of FGC exists in medical contexts in Mali. For it to be eliminated 1) The Ministry of Health must issue an order forbidding the practice; 2) A bill making the practice illegal in all health facilities needs to be introduced to the national assembly. 


\section{Impact of the interventions}

\section{Implication of health care personnel in the anti-FGC campaign}

One of the desired effects of the health-provider training was for them to commit to the fight against FGC and to become IEC extension agents. The great majority (88\%) thought the anti-FGC campaign was necessary. Ninety-one percent declared they wished to play a role in sensitizing or educating the population who visited their health facilities. Seven percent said they wished to treat the short term or long term complications of FGC.

Paradoxically, the data from the studies done before and after the training sessions with the providers show an increase in those who thought anti-FGC campaigns were necessary and a decrease in those willing to conduct IEC activities. (See Graph 10) This can be explained by the fact that, having received IEC training, these agents were expected to facilitate these activities, and that this constituted an additional burden to their workload.

\section{Graph 10: Providers view of their active role in anti-FGC activities}

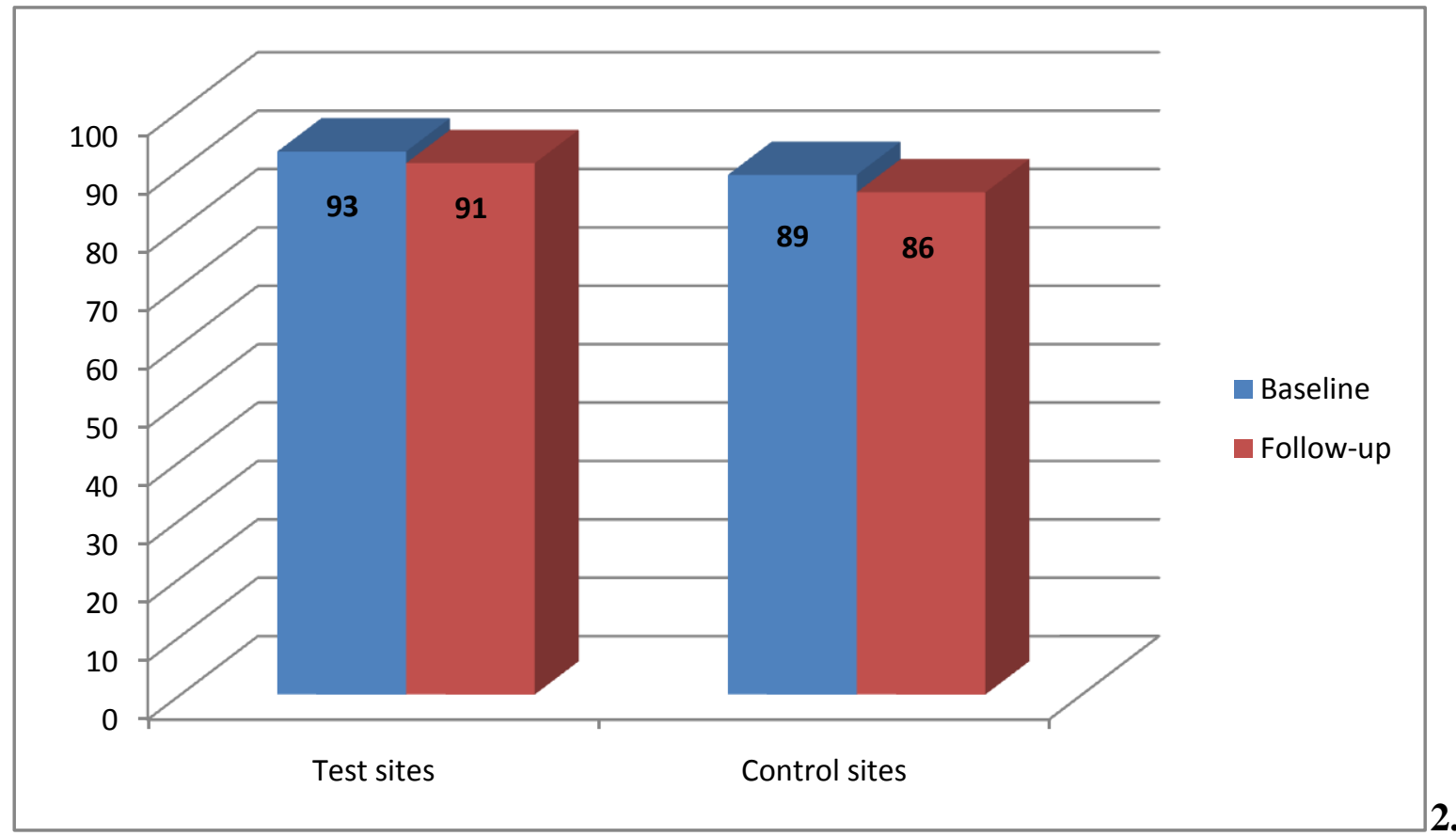

\section{IEC activities conducted in health service facilities}

An inventory guide of IEC materials was used in all researched sites to determine availability and IEC activities undertaken. Information on talks and counseling in the selected facilities was gathered from interviews conducted during one week in each facility.

The data showed that IEC material on reproductive health was available in all urban sites, but only in half of rural sites (2 CSAR and 1 CSCOM). All IEC tools were investigated, including posters, dummies, AV tools, flip charts. Graph 11 shows the IEC materials inventoried in the experimental and the control sites. 
All the test sites were provided with flip charts on FGC designed for the project. Only one test site could not find the device during the follow-up inventory. The great majority $(96 \%)$ of the health personnel interviewed who had used the visual aid said that it was useful or even essential in transmitting messages about FGC. Sixty-three percent found its use constraining, but $56 \%$ of these found it useful nevertheless. The material remained in good condition in all sites visited, fact which indicates it had not been put to extensive use.

\section{Graph 11: IEC materials in social/health service facilities of test and control sites}

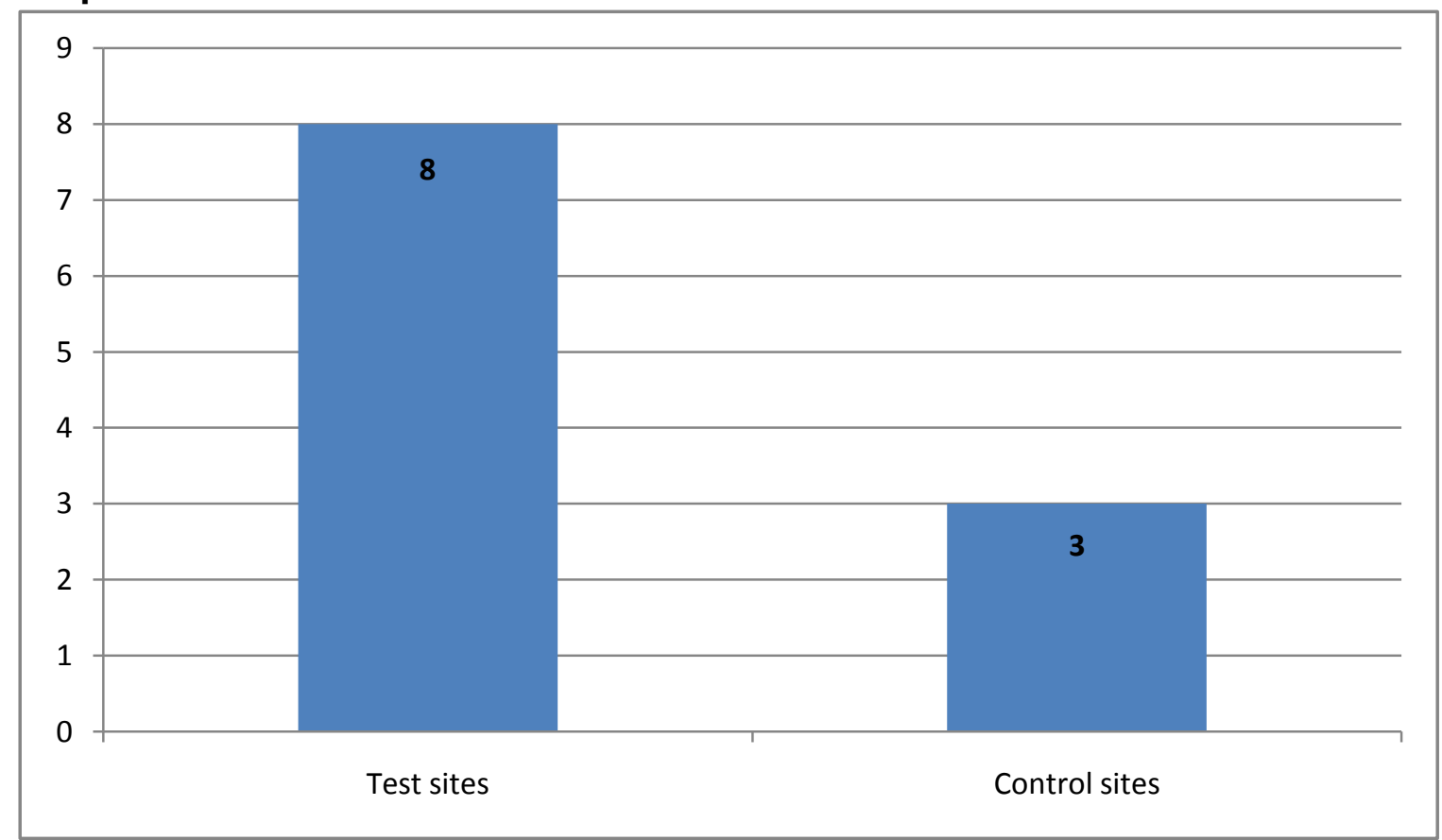

\section{Source: Inventory $n=14$}

IEC sessions or talks were held in only two of fourteen facilities. The health agents who facilitated these sessions were, for the most part, not trained in IEC and communication techniques. Some had experience is role playing techniques through this project training. Of those who had more IEC experience, few had worked on FGC issues previously.

This lack of properly trained facilitators is confirmed in a 1996 situational analysis report by the Family Planning services in Koulikoro and Sikasso which revealed that health personnel need to be better trained in IEC techniques and counseling. A 1998 national appraisal of IEC material also concluded that training is not adequate, that activities are rarely participative, and that few AV aids are used.

The study indicated that FGC counseling in rural zones of the test sites is more frequent than elsewhere. Half of the health providers who led IEC activities felt comfortable dealing with FGC issues. 
Among the total number of health agents who had received IEC training, more than half were unwilling to address FGC issues, compared to $1 / 3$ of those who had not been trained in communication techniques.

\section{Impact of the interventions on clients}

\section{IEC conducted in health facilities}

Interviews were conducted with outgoing clients in order to determine whether or not they had been exposed to FGC-related IEC sessions or counseling. The field researchers spent an entire week observing and interviewing in each site.

Questions were also asked about the time waiting to see the provider and the time of the actual consultation. These questions should have allowed an estimate of the time spent in counseling the client who would receive information on FGC issues. It appears that $66 \%$ of the clients waited over half an hour to see the provider. Only $9 \%$ were counseled during the visit. FGC issues were approached in half of these. The subjects of vaccination, nutrition, family planning, AIDS and post-natal care were also treated. Graph 12 shows whether or not clients had received counseling specifically related to FGC during their visits.

\section{Graph 12: FGC counseling given during client visits in test and control sites}

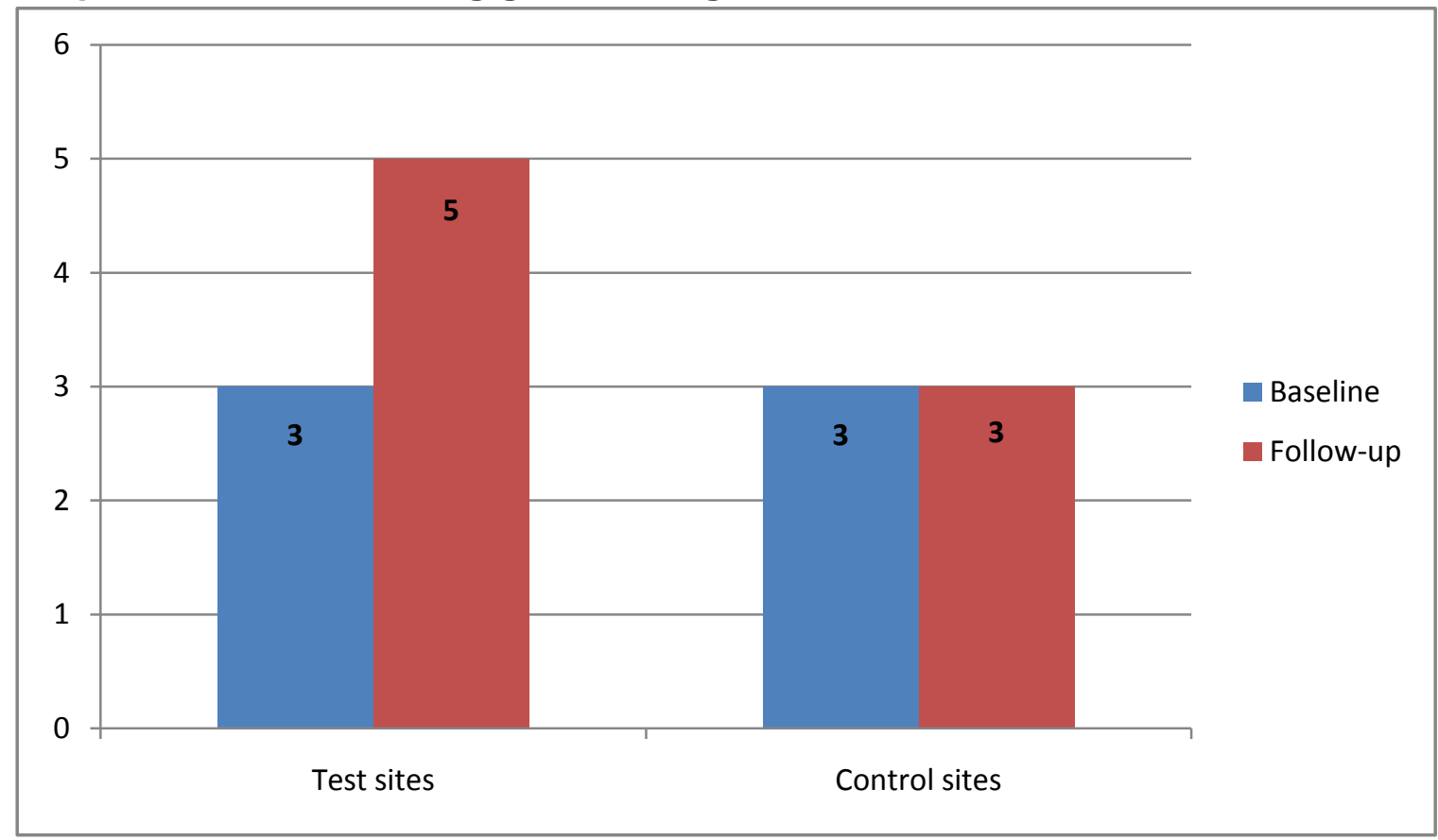

\section{Source: Inventory $n=14$}

A total of only $4 \%$ of the clients interviewed over one week in the test sites said they had received FGC-related information. The majority of these respondents were comfortable talking about FGC and interested in the subject. Those who had been counseled said the provider's presentation was easy to understand. However, $45 \%$ of the women interviewed declared they were informed of FGC issues from other sources, and the vast majority had 
been so informed in the two months preceding the follow-up research. Most of these respondents said they would talk about the issue with their family and friends. A definite interest in the issue was expressed.

Many providers did not fill in questions relating to IEC activities they might have conducted or counseling they might have given on the subject.

These data indicate that efforts need to be increased to engage medical personnel in the struggle against FGC.

\section{Clients' opinions of FGC}

As mentioned in the section concerning the limits of this study, the third hypothesis could not be confirmed. To verify if clients' attitudes toward FGC changed after they were exposed to IEC activities required a comparative analysis between the respondents in the test and the control groups. It was not possible to analyze this in the pilot study since very few IEC sessions or counseling were held for the clients in the test sites. Some data do, however, emerge from the clients' attitudes toward FGC.

Forty-nine percent of the clients interviewed said that traditions can evolve as the world does. Thirty-three percent said traditions are by definition immutable. Seventy-four percent said that a traditional practice which harms the health and well-being of the population should be abandoned. Forty percent of these cited FGC first.

The clients' opinions of FGC reflected, to some extent, those of the health providers. Forty percent of the women interviewed thought that non-circumcised girls had "looser morals" than those who had been circumcised. Thirty-five percent thought that men preferred to marry circumcised women. The majority of respondents (51\%) maintained that female circumcision was a religious obligation; 50\% thought the woman is cleaner after FGC; $51 \%$ thought FGC was a rite of passage which rendered their girls more responsible.

Sixty percent of clients interviewed declared they wished to have their girls circumcised. They justified this by respect of the tradition, concern for hygiene, and the control of feminine sexuality or the girl becoming a faithful wife.

\section{Attitudes of clients concerning FGC and health concerns}

As shown in Graph 13, contrary to the opinions expressed by the health providers, the majority of clients interviewed thought that FGC should be conducted in medical contexts in order to decrease the health risks. Only $18 \%$ of the respondents said the practice should be forbidden. Fifty-eight percent declared there should be no campaign to discourage female circumcision, a figure which corresponds to the $60 \%$ who have their daughters circumcised. 


\section{Graph 13: Clients' opinions regarding FGC as a safe practice if performed in a medical context}

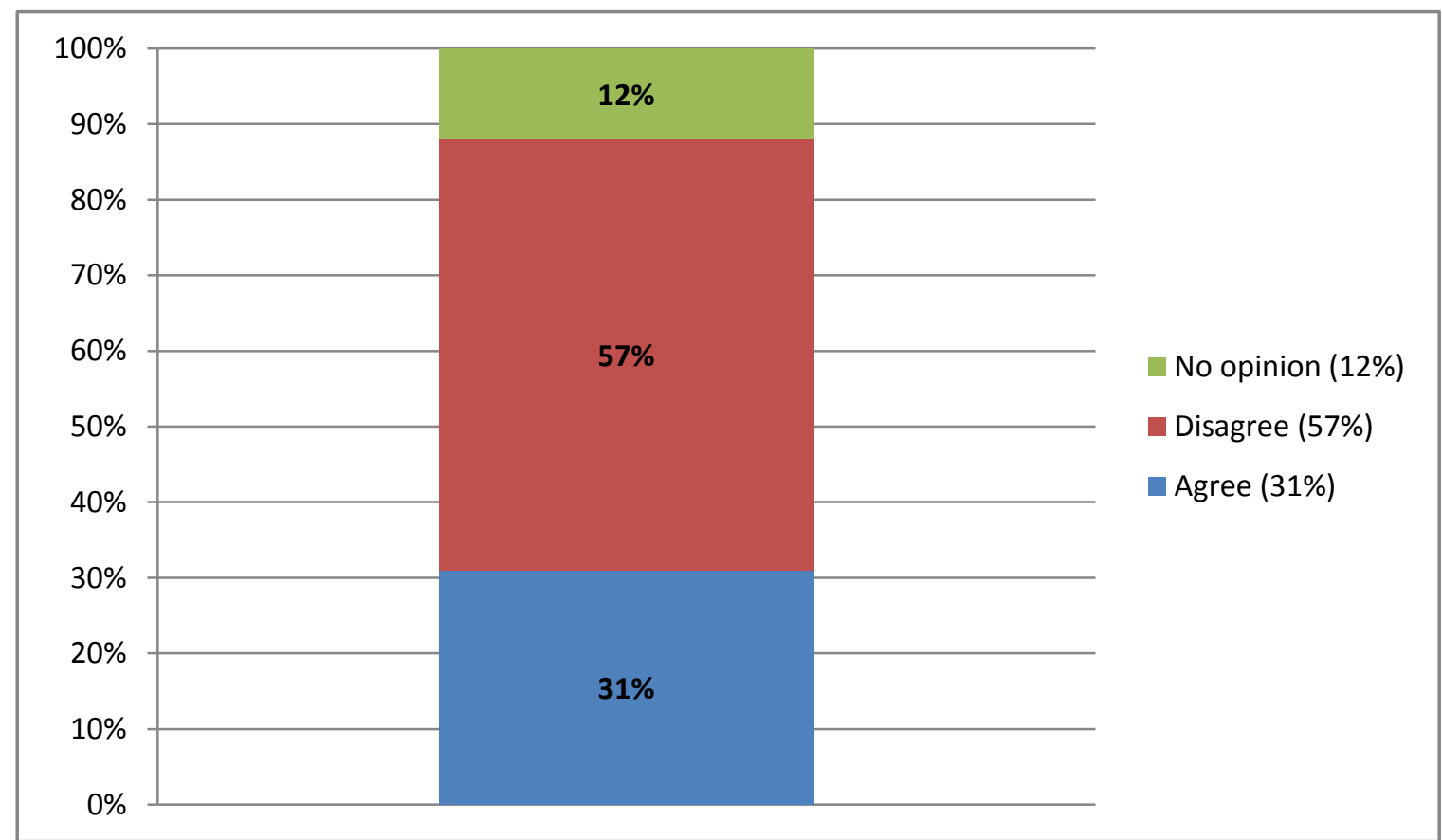

Source: Client interviews $n=1633$

\section{Conclusions and recommendations concerning IEC activities in health facilities}

* IEC activities do not often occur in health facilities. Greater emphasis has to be put on providers' involvement in these activities.

- The majority of providers who currently facilitate IEC activities have no appropriate training. The activities conducted should be more interactive. It is advisable to include education and communication agents in the IEC training and to organize sessions within the schedules of the facilities. FGC should figure systematically in the public forums and talks organized in OB-GYN and Family Planning services.

\section{OVERALL CONCLUSIONS AND RECOMMENDATIONS}

Even though the interventions of this pilot study did contribute to a change in FGC-related knowledge levels and capacity building of health providers, they had too small an impact on the attitudes toward FGC among the health providers or the population. Therefore, such efforts should be continued throughout the country.

Although IEC tools were available in the experimental sites, few activities were conducted. Providers cited several reasons for this, including the lack of an appropriate space, the lack of time, and discomfort in publicly broaching a taboo subject. The time span provided for IEC training was apparently too short and should be expanded. Curiously, it seems that 
providers who had received no training in communications techniques were those who most often facilitated FGG-related IEC sessions and counseling.

It appears that health facility clients need more information on FGC and its risks for very few are aware that the practice can lead to serious health complications. It would not be difficult to conduct awareness-raising activities since the clients are already receptive and interested in the subject.

This research has highlighted certain issues related to the practice of FGC in Mali, in particular health consequences and the role health personnel can play in eradicating the practice. The continued prevalence of FGC among dominant ethnic groups and the risk of its spreading to minority ethnic groups which do not traditionally circumcise females justify the continuation and extension of the campaign.

The great majority of women have their daughters cut simply to conform to social standards and tradition, because "everybody does it." It is an auspicious moment to campaign for change. Future research avenues, such as ways to improve IEC tools and training in health facilities, and improving outreach programs particularly among youths, should be explored. 


\section{Bibliography}

BOUARE Kadiatou. 1997. Excision: Aspects socio-juridiques. Mémoire de fin d'étude, ENA, Bamako, Mali.

DIALLO Habibatou. 1990. Aspects socio-sanitaires de l'excision au Mali. Thèse de Doctorat en Médecine, ENMP. Bamako, Mali.

DIALLO Assitan. 1996. Les Mutilations Génitales Féminine au Mali, Revue de la littérature et des actions de lutte. Bamako, Mali.

DIALLO Assitan. 1987. L'excision en milieu Bambara, Mémoire de fin d'étude, ENSUP, Bamako, Mali.

Coulibaly Salif and al. 1996. Enquête Démographique et de Santé II, Mali 1995-1996.

DIARRA Tiéman. 1997. C.A.P. des populations de 10 villages de l'arrondissement de Sanankoroba, Plan International, Bamako Mali.

KONE Agnès DEMBELE. 1985. Quelques coutumes qui nuisent à la santé de la femme: l'excision, l'infibulation. Mémoire de fin d'étude ENSUP, Bamako, Mali.

MAIGA Lala Mint DAHA. 1984. Conséquences gynéco-obstétricales de l'excision chez la femme malienne. Document de recherche, Bamako, Mali.

TOKINDANG, Joel et DIALLO Assitan. 1997. L'Excision au Mali: Une vision Prospective des Pratiques. Population Council Bamako, Mali.

TOUBIA, Nahid. 1993. Female Genital Mutilation: A Call for Global Action. Geneva, Switzerland: World Health Organization.

TOURE, Younoussa et al. 1997. L'excision au Mali: Réalités et perspectives de lutte. Bamako, Mali. 